\title{
A vertical ball mill as a new reactor design for biomass hydrolysis and fermentation process
}

de Assis Castro, Rafael Cunha; Mussatto, Solange I.; Conceicao Roberto, Inês

Published in:

Renewable Energy

Link to article, DOI:

10.1016/j.renene.2017.07.095

Publication date:

2017

Document Version

Peer reviewed version

Link back to DTU Orbit

Citation (APA):

de Assis Castro, R. C., Mussatto, S. I., \& Conceicao Roberto, I. (2017). A vertical ball mill as a new reactor design for biomass hydrolysis and fermentation process. Renewable Energy, 114(Part B), 775-780. https://doi.org/10.1016/j.renene.2017.07.095

\section{General rights}

Copyright and moral rights for the publications made accessible in the public portal are retained by the authors and/or other copyright owners and it is a condition of accessing publications that users recognise and abide by the legal requirements associated with these rights.

- Users may download and print one copy of any publication from the public portal for the purpose of private study or research.

- You may not further distribute the material or use it for any profit-making activity or commercial gain

- You may freely distribute the URL identifying the publication in the public portal 

hydrolysis and fermentation process

$6{ }^{1}$ Departamento de Biotecnologia, Escola de Engenharia de Lorena, Universidade de 7 São Paulo, CEP:12602-810, Lorena, São Paulo, Brazil.

${ }^{2}$ Novo Nordisk Foundation Center for Biosustainability, Technical University of Denmark, Kemitorvet, Building 220, 2800, Kongens Lyngby, Denmark.

*Corresponding author: Inês Conceição Roberto, Departamento de Biotecnologia,

13 Escola de Engenharia de Lorena, Universidade de São Paulo, Estrada Municipal do

14 Campinho, s/n ${ }^{\circ}$, CEP: 12.602-810, Lorena - São Paulo, Brazil. Tel: (+55) 12-3159-

15 5026. E-mail: ines@debiq.eel.usp.br 


\section{Abstract}

26 A vertical ball mill (VBM) reactor was evaluated for use in biomass conversion

27 processes. The effects of agitation speed (100-200 rpm), number of glass spheres (0-30

28 units) and temperature $\left(40-46^{\circ} \mathrm{C}\right)$ on enzymatic hydrolysis of rice straw and on glucose

29 fermentation by a thermotolerant Kluyveromyces marxianus strain were separately

30 studied. The results revealed an important role of the spheres during biomass' fiber

31 liquefaction and yeast's fermentative performance. For hydrolysis, the spheres were the

32 only variable with significant positive impact on cellulose conversion, while for

33 fermentation all the variables have influenced the ethanol volumetric productivity $\left(\mathrm{Q}_{\mathrm{P}}\right)$.

34 For $\mathrm{Q}_{\mathrm{P}}$, the spheres showed an interactive effect with temperature, being obtained a

35 maximum of $2.16 \mathrm{~g} / \mathrm{L} . \mathrm{h}$ when both variables were used in the lowest level. By applying

36 the needed adjustments on the levels of the variables for each process (hydrolysis and

37 fermentation), the VBM reactor could be efficiently used for biomass conversion into 38 ethanol.

40 Keywords: Non-conventional reactor; Rice straw; Enzymatic hydrolysis; Ethanol; $41 \quad$ Kluyveromyces marxianus 


\section{Introduction}

The use of lignocellulosic materials as feedstocks to produce fuels, power,

51 materials and chemicals is a promising and sustainable alternative to petroleum-based

52 platform. Lignocellulose is the fibrous part of plant materials, mainly composed of

53 cellulose, hemicellulose and lignin in a highly organized structure that makes the plant

54 biomass recalcitrant to physical, chemical and microbial attack [1]. Among the

55 lignocellulosic raw materials, rice straw (the stalk of the plant that is left over on the

56 field upon harvesting of the rice grain) is one of the main agricultural residues

57 worldwide, with an estimated availability of 685 million tons per year [2].

58 The conversion of polysaccharides from lignocellulosic materials into ethanol by

59 the biochemical route is performed in three steps: 1) biomass pretreatment to make

60 polysaccharides more accessible to further hydrolysis; 2) hydrolysis of polysaccharides

61 into monosaccharides by hydrolytic enzymes, and 3) fermentation of the obtained

62 sugars into ethanol [3]. However, there are still some aspects to be enhanced in order to

63 reach a more economically competitive technology, such as the slow rate of cellulose

64 enzymatic hydrolysis, low fermentation yield and productivity, the costs of the enzymes

65 and high-energy requirements [4]. To solve these issues, several efforts have been

66 carried out considering crops management, pretreatment methods, hydrolytic enzymes,

67 microorganisms, and bioreactor systems [5].

68 Regarding the pretreatment step, a variety of methods has been reported in the

69 literature with different specificities on altering the physical and chemical structure of

70 the lignocellulosic materials [6]. Considering the biorefinery approach, the pretreatment

71 technology must focus on biomass fractionation, not only improving the subsequent 
72 hydrolysis of cellulose, but also providing separation of the main constituents of

73 lignocellulosic biomass. In this way, each individual main component of biomass may

74 be handled toward different categories of products [7]. Nevertheless, depending on the

75 type of pretreatment and conditions employed, some biomass components can be lost

76 during this process [8]. The loss of these components, especially the polysaccharide

77 ones, must be avoided in order to increase the process efficiency. Recently, we have

78 proposed a two-steps pretreatment that improved the ethanol production from both

79 cellulose and hemicellulose fractions of rice straw [9]. This two-steps process consists

80 in applying a mild alkaline pretreatment to remove acetyl groups from the biomass

81 structure, prior to dilute acid hydrolysis to produce a hemicellulosic hydrolysate with

82 lower toxicity degree, thus obtaining a pretreated cellulose-rich solid (cellulignin) with

83 minimal loss of polysaccharide fractions.

84 In order to obtain soluble glucose from the cellulose fraction, the pretreated solid

85 must be submitted to an enzymatic hydrolysis step by the action of cellulases. However,

86 the heterogeneous nature of the biomass fibers creates rheological complexities,

87 hindering the mass transfer rate in the substrate matrix and limiting the cellulose

88 conversion [10]. In addition, as only a limited amount of free water is present when the

89 process is performed at high solids content, a much longer time is required to liquefy

90 the matrix to attain an effective hydrolysis [11]. Therefore, the reactor design plays an

91 important role to achieve an effective bioconversion process. In this sense, non-

92 conventional reactors with novel design and stirring modes have been suggested as a

93 possibility to overcome some of the mixing problems related to insoluble solids

94 liquefaction, as recently reviewed by Liguori et al. [5]. 
Within this context, this work aimed to evaluate the enzymatic hydrolysis of rice

96 straw in a non-conventional reactor, named a Vertical Ball Mill (VBM) reactor, as well

97 as to study the use of this reactor for ethanol production by fermentation using semi-

98 defined glucose medium. The effects of operational conditions including agitation

99 speed, number of glass spheres and temperature were investigated on each process. The

100 novelty of this research lies in the use of this new reactor design, regarding a conceptual

101 impeller type in combination with a grinding element. This study represents an initial

102 approach to estimate the efficiency of the VBM reactor for use in future SSF processes.

103

104 2. Materials and methods

105

$106 \quad$ 2.1. Feedstock and pretreatment

107 Rice straw was collected from fields in the region of Canas, São Paulo state,

108 Brazil. The material was dried until approximately $10 \%$ moisture content, hammer-

109 milled to attain particles of about $1 \mathrm{~cm}$ in length and $1 \mathrm{~mm}$ in thickness, and stored until

110 treatment. Milled rice straw was submitted to a two-steps pretreatment as previously

111 defined by Castro et al. [9]. Firstly, the material was deacetylated employing $\mathrm{NaOH}$

112 solution with a loading of $80 \mathrm{mg} \mathrm{NaOH} / \mathrm{g}$ of biomass, using a solid:liquid ratio of $1: 10$,

113 at $70{ }^{\circ} \mathrm{C}$ for $45 \mathrm{~min}$. After washing, the deacetylated solid material was pretreated by

114 dilute acid hydrolysis using $100 \mathrm{mg} \mathrm{H}_{2} \mathrm{SO}_{4} / \mathrm{g}$ deacetylated rice straw, a solid:liquid ratio

115 of $1: 10$, at $121^{\circ} \mathrm{C}$ for $85 \mathrm{~min}$. The resulting solid (referred as deacetylated cellulignin)

116 was washed and dried until $10 \%$ moisture content. The composition of the raw and

117 pretreated material was determined according to NREL-LAP standard protocol [12], as

118 shown in Table 1. 


\subsection{Enzymes and microorganism}

Cellulase from Trichoderma reesei (Cellubrix, Novozymes Corp.) with an activity

123 of $30 \mathrm{FPU} / \mathrm{mL}$ was used for enzymatic hydrolysis. Additional $\beta$-glucosidase produced

124 from Aspergillus niger (Novozyme 188, Novozymes Corp.) with an activity of 920

$125 \mathrm{IU} / \mathrm{mL}$ was also added to the experiments to enhance the cellulose conversion to 126 glucose.

The thermotolerant yeast Kluyveromyces marxianus NRRL Y-6860 was used for

128 fermentation. For inoculum preparation, cells from malt extract agar slants were

129 cultivated in Erlenmeyer flasks containing semi-defined medium with the following 130 composition (g/L): 30.0 glucose, $1.5 \mathrm{KH}_{2} \mathrm{PO}_{4}, 1.0\left(\mathrm{NH}_{4}\right)_{2} \mathrm{SO}_{4}, 0.1 \mathrm{MgSO}_{4} \cdot 7 \mathrm{H}_{2} \mathrm{O}$, and 1313.0 yeast extract. The inoculum was cultivated in an orbital shaker at $40{ }^{\circ} \mathrm{C}, 200 \mathrm{rpm}$ for $13216 \mathrm{~h}$. After this time, the cells were recovered by centrifugation $(2500 \times g, 10 \mathrm{~min})$, 133 washed twice in sterile distilled water, and resuspended in the fermentation medium to 134 obtain the desired initial cell concentration $(1.0 \mathrm{~g} / \mathrm{L})$.

\subsection{Vertical Ball Mill (VBM) reactor set-up}

A 1.5-L VBM reactor (120 mm inner diameter) made of 316 stainless steel and 138 jacketed for temperature control by water recirculation using an external thermostatic 139 water bath was used for the experiments. This reactor was equipped with three flat 140 round plates impellers of $94 \mathrm{~mm}$ diameter, which were positioned at a distance of 28 $141 \mathrm{~mm}$ each other, as shown in Fig. 1. Above each plate, glass spheres $(23 \mathrm{~mm}$ diameter 
and $8.16 \pm 0.35 \mathrm{~g}$ each) were placed as grinding elements. The impeller was rotated by an electric motor (IKA RW 20) able to operate from 60 to $2000 \mathrm{rpm}$.

\subsection{Enzymatic hydrolysis of pretreated rice straw in the VBM reactor}

A $2^{3}$ full-factorial experimental design, composed by 11 independent assays, was used to evaluate the effects of the following operational variables on enzymatic hydrolysis of pretreated rice straw in the VBM reactor: agitation (100 to $200 \mathrm{rpm})$, number of glass spheres ( 0 to 30$)$ and temperature $\left(40\right.$ to $\left.46^{\circ} \mathrm{C}\right)$. The experimental error was estimated by the three central points to give important information on the reproducibility of the experiments, which was considered into statistical analysis of

153 significance. All the experiments were conducted using $8 \%(\mathrm{w} / \mathrm{v})$ solid loading $(40 \mathrm{~g}$ 154 dry mass in $0.5 \mathrm{~L}$ final volume), $50 \mathrm{mM}$ sodium citrate buffer ( $\mathrm{pH} 4.8$ ), 21.5 FPU 155 cellulase/g cellulose and final $\beta$-glucosidase loading of $64.5 \mathrm{IU} / \mathrm{g}$ cellulose. The enzyme 156 solution was added after reaching the desired temperature, from which the reaction has 157 begun. Samples were taken at appropriate times to estimate glucose in order to assess 158 the kinetics of enzymatic hydrolysis in each evaluated condition, until $24 \mathrm{~h}$ process. 159 Cellulose conversion (CC) was the response considered for these experiments. CC was 160 calculated according to Eq. 1 where [G] is the glucose concentration in the supernatant 161 of the slurry (in grams per liter), $F_{C}$ is the fraction of cellulose in the substrate (in gram per gram), and $T_{S}$ is the initial solids content (in grams per liter).

$$
C C(\%)=\frac{[G] \times 0.9}{F_{C} \times T_{S}} \times 100
$$


The same $2^{3}$ full-factorial experimental design, composed by 11 independent assays, was also used to evaluate the effects of the same operational variables levels on

169 ethanol production in the VBM reactor. In the same way, the experimental error was 170 estimated by three central point replicates. All assays were carried out using a semi171 defined medium composed of $(\mathrm{g} / \mathrm{L}): 50.0$ glucose, $1.5 \mathrm{KH}_{2} \mathrm{PO}_{4}, 1.0\left(\mathrm{NH}_{4}\right)_{2} \mathrm{SO}_{4}, 0.1$ $172 \mathrm{MgSO}_{4} \cdot 7 \mathrm{H}_{2} \mathrm{O}$, and 3.0 yeast extract, in $0.5 \mathrm{~L}$ total final volume and employing $1 \mathrm{~g} / \mathrm{L}$ 173 initial cell concentration of $K$. marxianus NRRL Y-6860, added after reaching the 174 desired temperature, from which the reaction has begun. Samples were periodically 175 taken until $24 \mathrm{~h}$ to measure biomass, glucose and ethanol concentrations. The ethanol 176 yield $\left(\mathrm{Y}_{\mathrm{P} / \mathrm{S}}, \mathrm{g} / \mathrm{g}\right)$, determined by ratio between ethanol produced and glucose consumed, 177 and ethanol volumetric productivity $\left(\mathrm{Q}_{\mathrm{P}}, \mathrm{g} / \mathrm{L} . \mathrm{h}\right)$, calculated by the ratio between the 178 maximum ethanol concentration and the respective fermentation time, were the 179 responses considered for these experiments.

\subsection{Analyses}

182 Biomass concentration was determined from the cell optical density (OD) at 600 $183 \mathrm{~nm}$ measured in a UV-Vis Spectrophotometer (Genesys 10S, Thermo Fischer Scientific) 184 and converted to cell concentration using a suitable calibration curve OD $\times$ dry weight. 185 Glucose and ethanol concentrations were quantified by HPLC using a refractive index 186 detector (Agilent Technologies 1260 Infinity), a Bio-Rad Aminex HPX-87H column 187 (Bio-Rad, Hercules, CA, USA) at $45^{\circ} \mathrm{C}$, and sulfuric acid $(0.005 \mathrm{M})$ as the mobile 188 phase in a flow rate of $0.6 \mathrm{~mL} / \mathrm{min}$. 


\subsection{Effect of operational conditions on enzymatic hydrolysis and fermentation} process

The results obtained for enzymatic hydrolysis of pretreated rice straw and glucose fermentation from semi-defined medium using the VBM reactor and the different

Table 2

\subsubsection{Enzymatic hydrolysis}

As can be seen in Table 2, the cellulose conversion of pretreated rice straw after $24 \mathrm{~h}$ varied from 68 to $87 \%$. The highest results (84-87\%) were obtained in the assays 7 observed in the assays 1 and 2, which were conducted without spheres and under the

206 of spheres and temperature have favored the cellulose conversion. This behavior 207 supports the hypothesis that the spheres can act as effective grinding agents, by causing 208 mechanical stress on biomass's fiber, which in turn improved the superficial contact 209 between enzyme and substrate. In general, mass and heat transfer problems stand up as 210 an important drawback in the bioconversion process, especially on the enzymatic 211 hydrolysis step [13]. Samaniuk et al. [14] verified a synergistic relationship between 212 mixing and enzyme activity during enzymatic hydrolysis. According to the authors, in 213 mixed systems, the enzyme distribution is improved and the particle surface area rapidly 214 decreases during the hydrolysis that in turn reduces the mass transfer limitations. 
Some authors have described new reactor configurations and agitation systems in

216 order to improve the enzymatic hydrolysis of lignocellulosic materials. For example,

217 Kadić et al. [15] investigated the effect of agitation rate on enzymatic hydrolysis of

218 steam pretreated Arundo donax and spruce in reactor equipped with a pitched-blade

219 impeller with three blades at an angle of $45^{\circ}$. The authors observed an improvement in

220 the hydrolysis rate from 20 to $37 \%$ using spruce $(13 \% \mathrm{w} / \mathrm{w})$ when the impeller speed

221 was increased from 100 to $600 \mathrm{rpm}$. Such improvement was related to the reduction of

222 particle size, which increased the hydrolysable surface area. Another example was

223 reported by $\mathrm{Du}$ et al. [16] who compared the enzymatic hydrolysis of sulfuric

$224 \mathrm{acid} / \mathrm{steam}$ pretreated corn stover employing two different reactor systems, the

225 horizontal rotating bioreactor (HRR) and the vertical stirred-tank reactor (VSTR),

226 equipped with a double helical ribbon impeller. The authors reported that HRR's

227 performance on biomass saccharification at $25 \%(\mathrm{w} / \mathrm{w})$ was about $18 \%$ higher than that

228 of VSTR.

229 A combined strategy of simultaneous ball milling and enzymatic hydrolysis was

230 evaluated by Mais et al. [17] using a 1.1-L ball-mill reactor and small porcelain beads as

231 grinding elements. According to these authors, increasing the numbers of beads present

232 in the reaction vessel improved the efficacy of hydrolysis conversion of $\alpha$-cellulose at 5

$233 \%(\mathrm{w} / \mathrm{v})$. The conversion yields after $48 \mathrm{~h}$ were 67,66 , and $73 \%$ with 0,50 , and 100

234 beads, respectively.

235 The results of the present study on enzymatic hydrolysis of deacetylated rice straw

236 cellulignin in the VBM reactor are also promising and represent a significant

237 improvement in process efficiency. For example, under the conditions of assay 7 (100

$238 \mathrm{rpm}, 30$ spheres, $46{ }^{\circ} \mathrm{C}$ ) a cellulose conversion of $87 \%$ was achieved at $24 \mathrm{~h}$, while 
under the same process conditions but in the absence of spheres (assay 5), the cellulose

240 conversion was reduced to $73.4 \%$. These results are also better when compared to a

241 previous study performed in shake flasks [18], which resulted in $79.2 \%$ conversion at 48

242 h, employing the same solids content and enzyme loading. Fig. 2 shows the kinetic

243 profile of enzymatic hydrolysis performed in both experiments. As can be seen, the

244 cellulose conversion rate was mainly enhanced in the first $24 \mathrm{~h}$ of process, reaching

$24510 \%$ improvement when using the VBM reactor and the conditions of assay $7(100 \mathrm{rpm}$,

24630 spheres and $46{ }^{\circ} \mathrm{C}$ ). Besides reducing the hydrolysis time in $24 \mathrm{~h}$, improving the

247 cellulose conversion in approx. $10 \%$ is relevant from the economical point of view,

248 since the literature has reported a great impact of this step on second-generation ethanol

249 production costs [19].

Figure 2

The present results demonstrate that the new VBM reactor used in this study can be efficiently employed for saccharification of lignocellulosic raw materials.

\subsubsection{Fermentation process}

255 The effects of the same operational conditions previously studied in the VBM 256 reactor for enzymatic hydrolysis were also evaluated on ethanol production from 257 glucose using the yeast K. marxianus. As can be seen in Table 2, in the studied range of 258 values, $\mathrm{Y}_{\mathrm{P} / \mathrm{S}}$ showed a little variation (from 0.38 to $0.44 \mathrm{~g} / \mathrm{g}$ ), whereas $\mathrm{Q}_{\mathrm{P}}$ showed a more 259 significant variation (from 0.74 to $2.16 \mathrm{~g} / \mathrm{L} . \mathrm{h}$ ). K. marxianus was able to convert 260 glucose into ethanol with high efficiency ( $80 \%$ in average) even at the highest 261 temperature (assays 5-8), regardless of the agitation speed and number of spheres, thus 262 confirming its thermotolerant characteristic. Glucose consumption was also higher than $26381 \%$ for all the experiments. On the other hand, cultivation at the highest temperature 
264 resulted in the lowest cell growth $(<1.5 \mathrm{~g} / \mathrm{L})$ and ethanol volumetric productivity $(<0.9$ 265 g/L.h).

266 It is interesting to note in Table 2 that the conditions of the assay 7, which 267 provided the highest cellulose conversion by enzymatic hydrolysis (87\%), resulted in 268 the lowest value of $\mathrm{Q}_{\mathrm{P}}(0.74 \mathrm{~g} / \mathrm{L} . \mathrm{h})$. Such results indicate that the conditions that 269 enhanced enzymatic hydrolysis were different from those that benefited the 270 fermentative process in the VBM reactor. In order to better understand the effects of the 271 process variables on both processes (hydrolysis and fermentation), a statistical analysis 272 of the data was performed, as follows.

\subsection{Statistical analysis}

Pareto's charts (a graphical representation of Student's $t$-test) representing the estimated effects and interaction of the independent variables on the evaluated

277 responses are shown in Fig. 3. In these charts, the bars beyond the vertical line 278 correspond to effects significant at $p<0.05$.

For cellulose conversion (Fig. 3A), the number of spheres was the only variable with a significant individual effect, which was positive suggesting that increasing the number of spheres improved the efficiency of hydrolysis. Regarding the fermentation process, the three studied variables (agitation, number of spheres and temperature)

285 them had a significant effect on $\mathrm{Y}_{\mathrm{P} / \mathrm{S}}$ (Fig. 3C). These results suggest that the ability of 286 the yeast to convert glucose into ethanol was not affected by varying the process 
conditions, but the conversion rate was strongly dependent on the level of the variables

288 employed for fermentation.

289 Besides the individual effects, two interactions were also significant for the 290 response QP (Fig. 3C). The interaction between agitation speed and temperature had a 291 negative effect $\left(X_{1} \cdot X_{3}=-4.22\right)$ on this response, suggesting that $\mathrm{Q}_{\mathrm{P}}$ is positively 292 impacted by decreasing the temperature and increasing the agitation speed. In addition, 293 the temperature showed an interaction effect with the number of spheres, but with a 294 positive signal $\left(X_{2} \cdot X_{3}=+3.37\right)$, indicating that $\mathrm{Q}_{\mathrm{P}}$ increases in the conditions of lower 295 temperature and number of spheres. It is worth mentioning that $\mathrm{Q}_{\mathrm{P}}$ was increased in 296 about 3 -fold when the agitation speed was increased from 100 to $200 \mathrm{rpm}$ and the 297 temperature was reduced from 46 to $40^{\circ} \mathrm{C}$, in the absence of glass spheres.

298 A multiple regression analysis of the results was performed in order to obtain 299 mathematical models explaining the variation of both responses as a function of the 300 operational variables. Linear models were adjusted with $\mathrm{R}^{2}$ equal to 0.84 for cellulose 301 conversion and 0.98 for $\mathrm{Q}_{\mathrm{P}}$, which explain 84 and $98 \%$ of the total variation in the 302 responses, respectively (Table 3).

Table 3

Contour surfaces plotted for the evaluated responses according to the previous established models (Fig. 4) clearly show that the enzymatic hydrolysis and fermentation processes are maximized in different regions. The effect of the spheres was the most reactor improved the cellulose conversion during the enzymatic hydrolysis of pretreated rice straw. However, the presence of spheres decreased the ethanol productivity during the fermentation step. The positive effect of the spheres on hydrolysis could be 
311 attributed to two types of phenomena: 1) shear stress due to impacts of the spheres on

312 lignocellulosic fibers and/or 2) increased mass transfer due to the generation of a more

313 homogeneous mixture during the hydrolysis. On the other hand, the negative effect of

314 the spheres on fermentation performance could be explained by possible viability losses

315 of the cells because of the shear stress generated.

Figure 4

317 Fig. 5 shows the kinetic profile of fermentation process performed in the VBM 318 reactor compared with that observed in the shake flasks experiments previously reported 319 by Ref. [18]. As can be seen, experiments in the VBM reactor under the conditions of 320 assay 2 showed ethanol concentration similar to that obtained in shake flasks (20.9 and $32120.1 \mathrm{~g} / \mathrm{L}$, respectively). However, a longer time was required to obtain this ethanol titer 322 in the VBM reactor, thus leading to a lower ethanol volumetric productivity.

Figure 5

\section{Conclusions}

The results of the present study indicate that the VBM reactor significantly 327 improved the saccharification of alkali-acid-pretreated rice straw. The glass beads added 328 to the VBM reactor was the main factor affecting both processes, enzymatic hydrolysis 329 and fermentation, with a positive effect on cellulose conversion and a negative effect on 330 ethanol volumetric productivity. Therefore, by applying the needed adjustments on the 331 levels of the variables for each process (hydrolysis and fermentation), the VBM reactor 332 could be efficiently used for biomass conversion in ethanol, presenting also potential for 333 use in SSF process, for example. Future studies would be useful in order to better 334 understand the fluid dynamics involved in VBM reactor, especially when operating with 
high solids content. Such information, together with the results of the present work, will

336 represent a step forward towards the development of the market in this sector.

338 Acknowledgements

339 Authors are gratefully acknowledging the financial assistance from the Fundação de 340 Amparo à Pesquisa do Estado de São Paulo (FAPESP) of Brazil [Proc. No 2013/139533416 and 2015/24813-6]. The authors also acknowledge the Coordenação de 342 Aperfeiçoamento de Pessoal de Nível Superior (CAPES) and Conselho Nacional de 343 Desenvolvimento Científico e Tecnológico (CNPq) of Brazil.

\section{References}

[1] S. Imman, J. Arnthong, V. Burapatana, V. Champreda, N. Laosiripojana. Fractionation of rice straw by a single-step solvothermal process: Effects of solvents, acid promoters, and microwave treatment. Renew. Energy 83 (2015) 663-673. doi:10.1016/j.renene.2015.04.062.

[2] J.S. Lim, Z. Abdul Manan, S.R. Wan Alwi, H. Hashim. A review on utilisation of biomass from rice industry as a source of renewable energy. Renew. Sustain. Energy Rev. 16 (2012) 3084-3094. doi:10.1016/j.rser.2012.02.051.

[3] S.I. Mussatto, G. M. Dragone, P.M.R. Guimarães, J.P.A. Silva, L.M. Carneiro, I.C. Roberto, A. Vicente, L. Domingues, J.A. Teixeira. Technological trends, global market, and challenges of bio-ethanol production. Biotechnol. Adv. 28 (2010) 817-830. doi: 10.1016/j.biotechadv.2010.07.001.

[4] S.I. Mussatto. A closer look at the developments and impact of biofuels in transport 
and environment; what are the next steps? Biofuel Res. J. 9 (2016) 331-331. doi: 10.18331/BRJ2016.3.1.2

[5] R. Liguori, V. Ventorino, O. Pepe, V. Faraco. Bioreactors for lignocellulose conversion into fermentable sugars for production of high added value products. Appl. Microbiol. Biotechnol. 100 (2016) 597-611. doi:10.1007/s00253-015-7125-9.

[6] S.I. Mussatto. Biomass fractionation technologies for a lignocellulosic feedstock based biorefinery. Elsevier Inc., Waltham, MA, 2016.

[7] S.I. Mussatto, G.M. Dragone, G.M. Biomass pretreatment, biorefineries and potential products for a bioeconomy development. In: Biomass fractionation technologies for a lignocellulosic feedstock based biorefinery. Mussatto, S.I. (Ed.), Elsevier Inc., Waltham, MA., 2016, pp. 1-22. doi: 10.1016/B978-0-12-802323-5.000013

[8] B. Guo, Y. Zhang, G. Yu, W-H Lee, Y-S. Jin, E. Morgenroth. Two-stage acidicalkaline hydrothermal pretreatment of lignocellulose for the high recovery of cellulose and hemicellulose sugars. Appl. Biochem. Biotechnol. 169 (2013) 1069-87. doi:10.1007/s12010-012-0038-5.

[9] R.C.A. Castro, B.G. Fonseca, H.T.L. Santos, I.S. Ferreira, S.I. Mussatto, I.C. Roberto. Alkaline deacetylation as a strategy to improve sugars recovery and ethanol production from rice straw hemicellulose and cellulose. Ind. Crops Prod. In press, (2016) 1-6. doi:10.1016/j.indcrop.2016.08.053

[10] D.M. Lavenson, E.J. Tozzi, N. Karuna, T. Jeoh, R.L. Powell, M.J. McCarthy. The effect of mixing on the liquefaction and saccharification of cellulosic fibers. Bioresour. Technol. 111(2012) 240-247. doi:10.1016/j.biortech.2012.01.167

[11] X. Zhang, W. Qin, M.G. Paice, J.N. Saddler.High consistency enzymatic 
hydrolysis of hardwood substrates. Bioresour. Technol. 100 (2009) 5890-7. doi:10.1016/j.biortech.2009.06.082

[12] A. Sluiter, B. Hames, R. Ruiz, C. Scarlata, J. Sluiter, D. Templeton, D. Crocker. Determination of Structural Carbohydrates and Lignin in Biomass, Lab. Anal. Proced. NREL/TP-510-42618 ( 2012) Golden, Colorado.

[13] B. Palmqvist, M. Wiman, G. Lidén, Effect of mixing on enzymatic hydrolysis of steam-pretreated spruce: a quantitative analysis of conversion and power consumption. Biotechnol. Biofuels 4 (2011), doi:10.1186/1754-6834-4-10.

[14] J.R. Samaniuk, C.T. Scott, T.W. Root, D.J. Klingenberg. The effect of high intensity mixing on the enzymatic hydrolysis of concentrated cellulose fiber $\begin{array}{lllll}\text { suspensions. } & \text { Bioresour. } & \text { Technol. } & 102 & \text { (2011) 4489-94. }\end{array}$ doi:10.1016/j.biortech.2010.11.117

[15] A. Kadić, B. Palmqvist, G. Lidén. Effects of agitation on particle-size distribution and enzymatic hydrolysis of pretreated spruce and giant reed. Biotechnol. Biofuels 7 (2014) doi:10.1186/1754-6834-7-77

[16] J. Du, F. Zhang, Y. Li, H. Zhang, J. Liang, H. Zheng, H. Huang. Enzymatic liquefaction and saccharification of pretreated corn stover at high-solids concentrations in a horizontal rotating bioreactor. Bioprocess Biosyst. Eng. 37 (2014) 173-181. doi:10.1007/s00449-013-0983-6

[17] U. Mais, A.R. Esteghlalian, J.N. Saddler, S.D. Mansfield. Enhancing the enzymatic hydrolysis of cellulosic materials using simultaneous ball milling. Appl. Biochem. Biotechnol. 98-100 (2002) 815-32.

[18] R.C.A. Castro, I.C. Roberto. Selection of a thermotolerant Kluyveromyces marxianus strain with potential application for cellulosic ethanol production by 
simultaneous saccharification and fermentation. Appl. Biochem. Biotechnol. 172 (2014) 1553-1564. doi:10.1007/s12010-013-0612-5.

[19] A.A. Modenbach, S.E. Nokes. Enzymatic hydrolysis of biomass at high-solids loadings - A review. Biomass and Bioenergy $56 \quad$ (2013) 526-544. doi:10.1016/j.biombioe.2013.05.031. 


\section{Figure Captions}

Figure 1. Image of the Vertical Ball Mill (VBM) reactor (A). Illustration of inside details (B): inlet (1) and outlet (2) water for temperature control; sampling duct (3); port for addition of reaction components (4); gases outlet port (5); agitation rotor (6); flat round impellers with spheres (7). Image (C) and illustration (D) of impellers.

Figure 2. Kinetic profile of cellulose conversion from pretreated rice straw biomass using the VBM reactor (present study) and shake flasks experiments from Castro and Roberto (2014).

Figure 3. Pareto's charts for the effects of agitation $\left(X_{1}\right)$, number of spheres $\left(X_{2}\right)$, temperature $\left(X_{3}\right)$ and their interactions on cellulose conversion by enzymatic hydrolysis, CC (A), ethanol volumetric productivity, $\mathrm{Q}_{\mathrm{P}}(\mathrm{B})$ and ethanol yield, $\mathrm{Y}_{\mathrm{P} / \mathrm{S}}(\mathrm{C})$ during fermentation using the VBM reactor.

Figure 4. Contour surfaces plotted according to the models representing (A) cellulose conversion and (B) ethanol volumetric productivity. The agitation speed was set at 150 rpm for both responses.

Figure 5. Ethanol production from glucose fermentation using the VBM reactor (present study) and shake flasks experiments from Castro and Roberto (2014). 
Table 1. Chemical characterization of raw material before (rice straw) and after pretreatment (deacetylated cellulignin).

\begin{tabular}{|l|c|c|}
\hline \multirow{2}{*}{ Components } & \multicolumn{2}{|c|}{ Composition (wt\%) } \\
\cline { 2 - 3 } & Rice straw & Deacetylated cellulignin \\
\hline Cellulose & $35.3 \pm 0.2$ & $61.8 \pm 0.7$ \\
\hline Hemicellulose & $23.8 \pm 0.4$ & $0.06 \pm 0.01$ \\
\hline Acetyl groups & $2.6 \pm 0.4$ & $11.1 \pm 0.1$ \\
\hline Lignin & $17.5 \pm 0.5$ & $0.9 \pm 0.1$ \\
\hline \multicolumn{1}{|c|}{ Acid soluble lignin } & $4.4 \pm 0.2$ & $16.2 \pm 0.6$ \\
\hline \multicolumn{1}{|c|}{ Acid insoluble lignin } & $13.1 \pm 0.7$ & $6.0 \pm 0.1$ \\
\hline Ash & $11.3 \pm 0.1$ & nd \\
\hline Extractives & $14.0 \pm 0.2$ & \\
\hline
\end{tabular}

nd: non- determined 


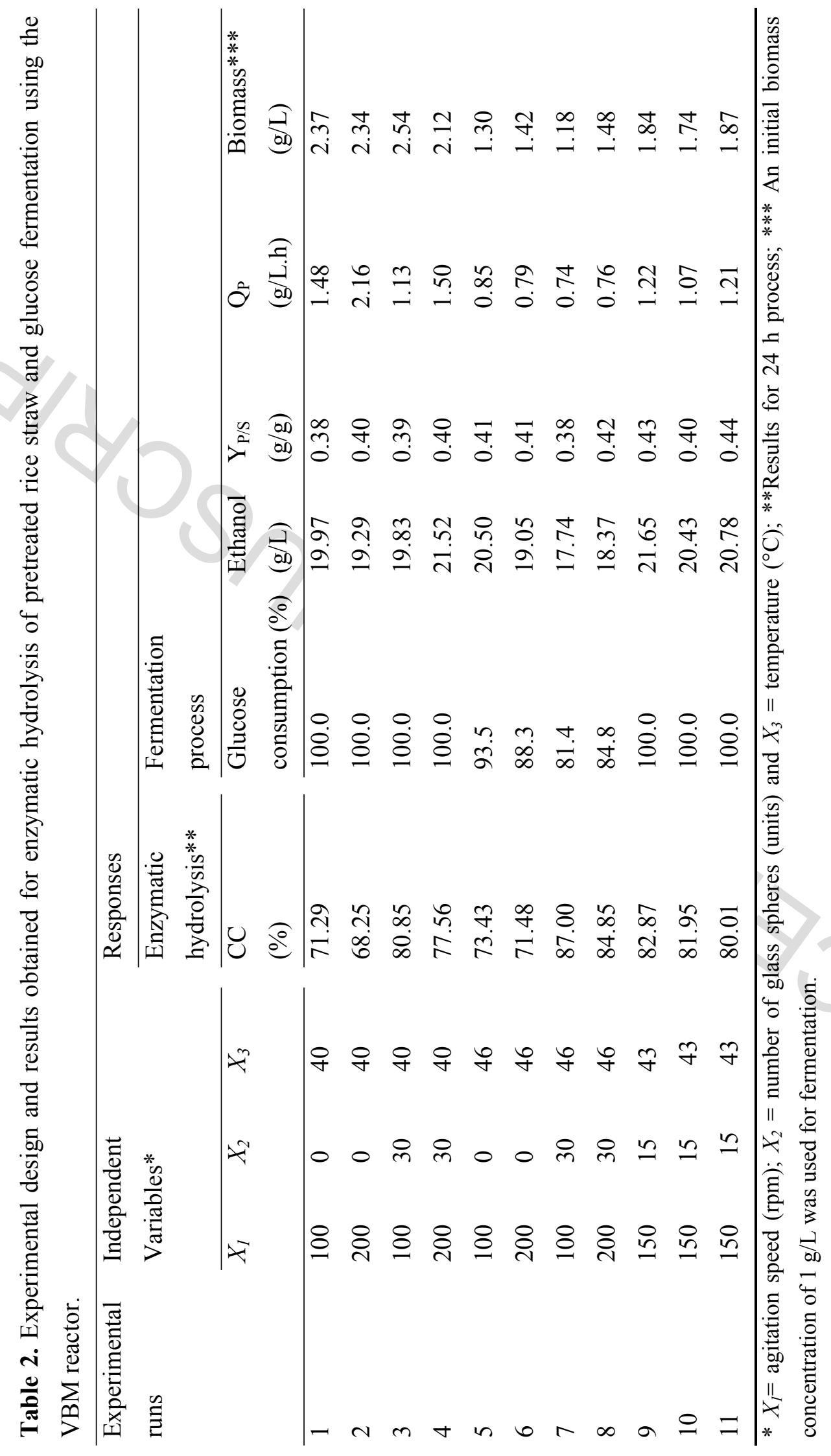


Table 3. Model equations for the responses cellulose conversion, $\mathrm{CC}$ in $\%\left(\hat{y}_{1}\right)$ and ethanol volumetric productivity, $\mathrm{Q}_{\mathrm{P}}$ in $\mathrm{g} / \mathrm{L} . \mathrm{h}\left(\hat{y}_{2}\right)$ during the processes of enzymatic hydrolysis and fermentation, respectively, in the VBM reactor.

\begin{tabular}{|l|l|}
\hline Model equation & $\mathrm{R}^{2}$ \\
\hline$\hat{y}_{1}=42.62-0.03 X_{1}+0.38 X_{2}+0.78 X_{3}$ & 0.84 \\
\hline$\hat{y}_{2}=2.25+0.04 X_{1}-0.11 X_{2}-0.03 X_{3}-0.001 X_{1} X_{3}+0.002 X_{2} X_{3}$ & 0.98 \\
\hline
\end{tabular}

$X_{1}, X_{2}, X_{3}$ represent the coded levels of agitation speed, number of spheres and temperature, respectively. 

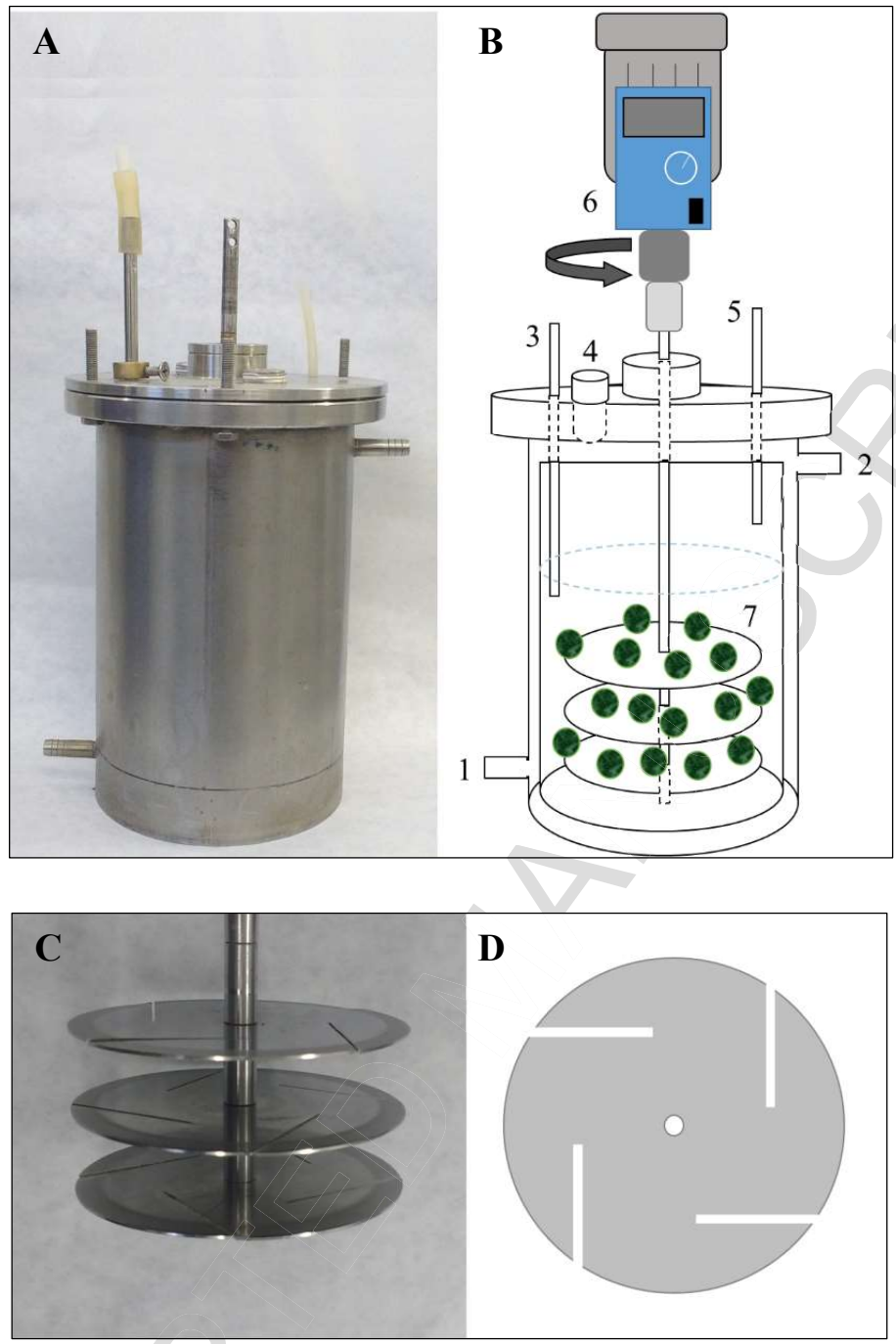

Figure 1 


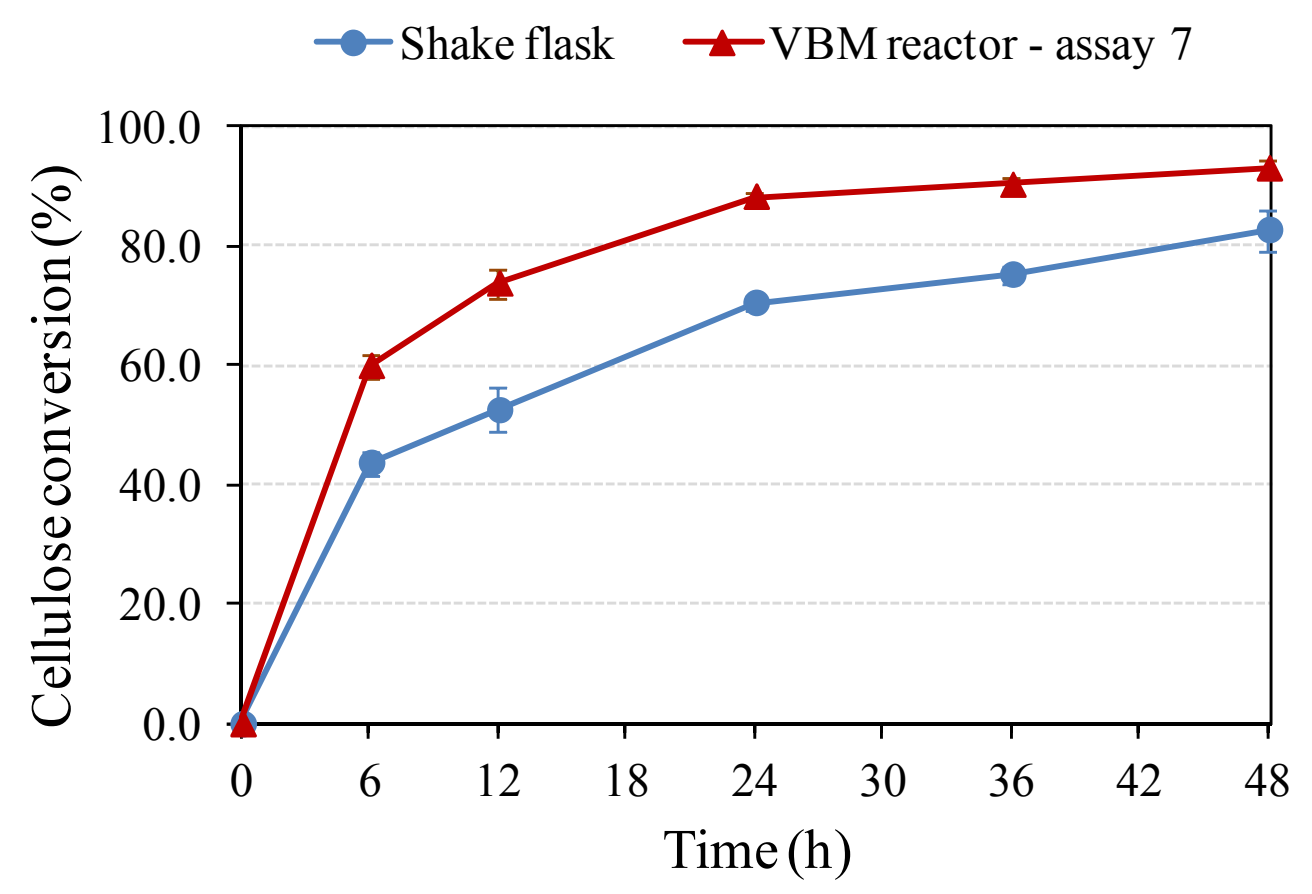

Figure 2 

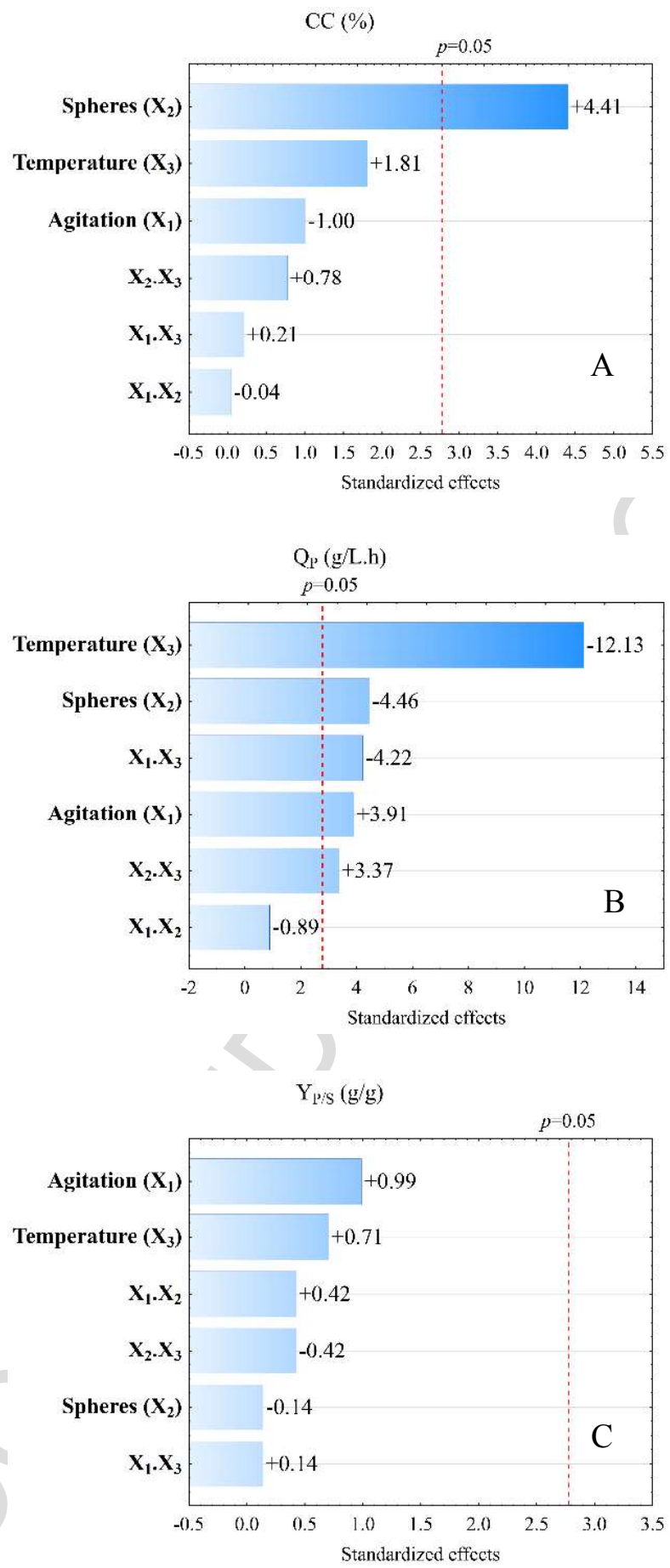

Figure 3 
(A)

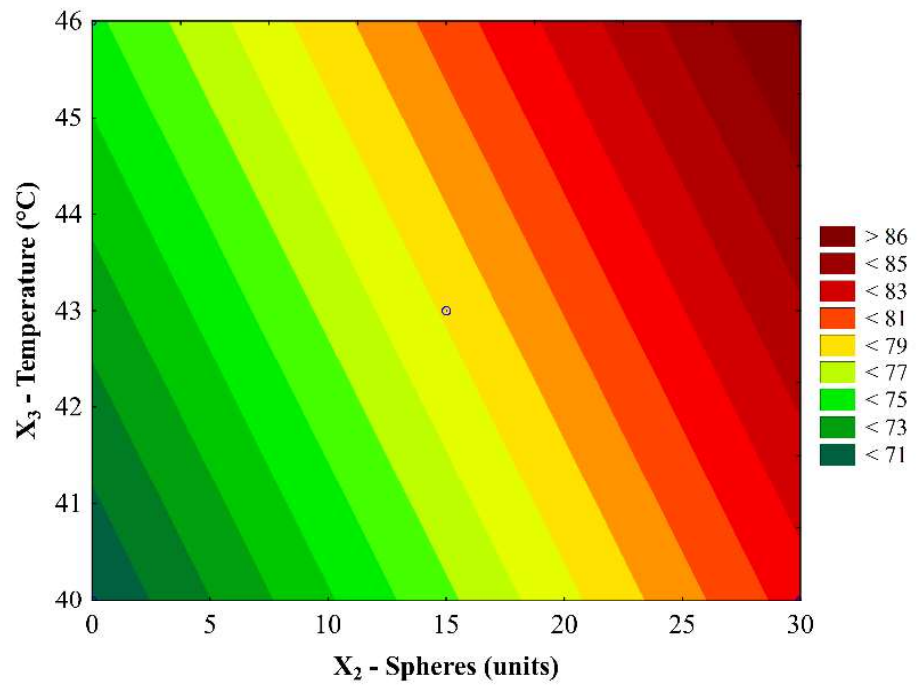

(B)

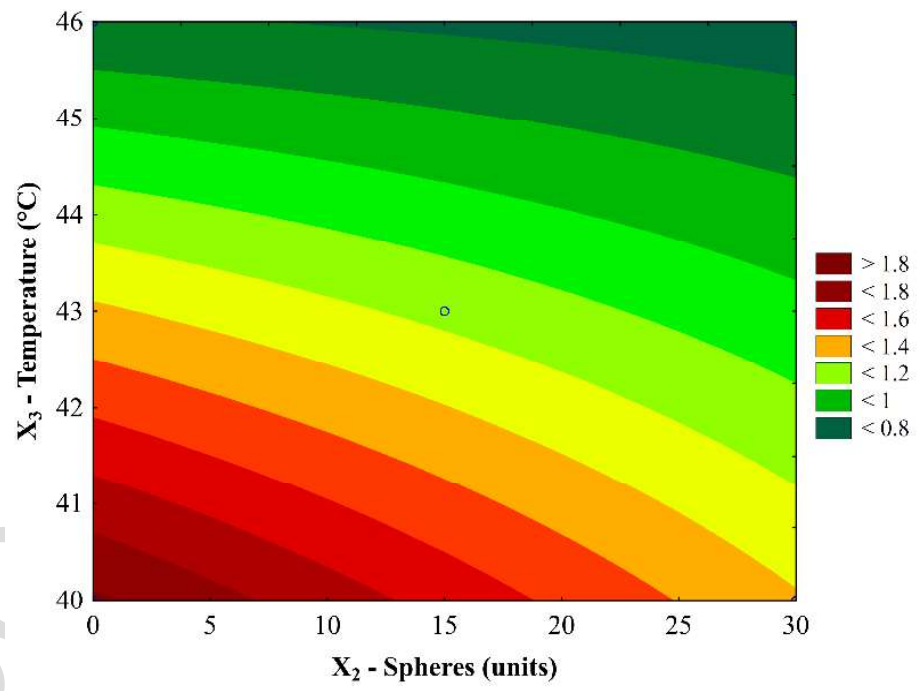

Figure 4 


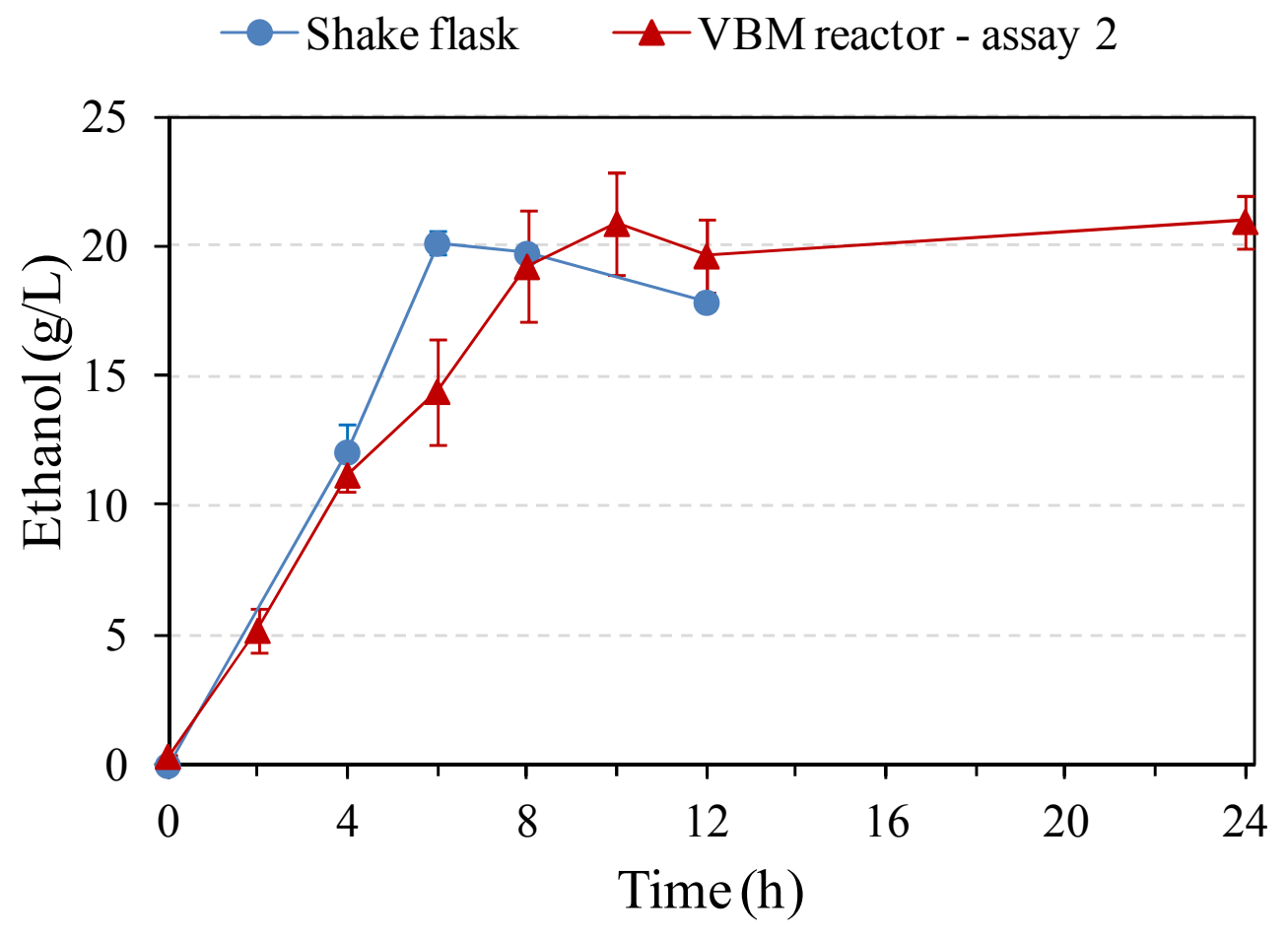

Figure 5 


\section{Highlights}

- A vertical ball mill (VBM) reactor was proposed for biomass conversion

- Enzymatic hydrolysis of rice straw and glucose fermentation were studied

- VBM significantly improved the enzymatic hydrolysis of pretreated rice straw

- Kluyveromyces marxianus showed high ethanol efficiency in the VBM reactor

- Operational conditions for each process in the VBM reactor were established 